\title{
El Doctor Juan Marín Rojas Primer Profesor de Historia de la Medicina de la Universidad de Chile y su "Ensayo Sobre el Origen de la Sífilis"
}

\author{
Enrique Laval
}

\section{Juan Marin Rojas M.D., First Professor of History of Medicine at Universidad de Chile and his "Essay about the origin of syphilis"}

Dr. Juan Marín Rojas, M.D., was the first Professor of History of Medicine at Universidad de Chile, navy doctor, diplomat, writer and literary critic. Member of the International Society of History of Medicine, and Correspondent Member for Chile of the "Office de Documentation de Médecine et Pharmacie Militaire", Liege, Belgium, from which his "Essay about the origin of syphilis" is transcribed with interesting historical facts and little known arguments that affirm the non-american origin of syphilis, but "aspire to leave a doubt, given not a contrary conviction".

Key words: Syphilis, origin, history.

Palabras clave: Sífilis, origen, historia.
Pontificia Universidad Católica de Chile.

Programa de Estudios Médicos Humanísticos Facultad de Medicina

Recibido: 21 de abril de 2014

Correspondencia a:

Enrique Laval Román revinf@sochinf.cl

\section{Notas biográficas sobre el Doctor Juan Marín Rojas}

$\mathrm{E}$ 1 profesor Lucas Sierra, que sentía especial predilección por los estudios médicos-históricos, confió a su ayudante, el doctor Juan Marín Rojas, que ya se había destacado como escritor de estilo pulcro y elegante, rico en imágenes y hondo en conceptos, que dictara un curso de Historia de la Medicina, en calidad de profesor agregado, cumpliendo fielmente la tarea.

El 25 de abril de 1932, en el Salón de Honor de la Universidad de Chile, el doctor Marín, dictó la lección inaugural del Curso de Historia de la Medicina, comenzando por rendir un homenaje al profesor Lucas Sierra y en parte de su exposición dijo que "en la Historia de la Medicina hay una mezcla de leyenda y de historia: hay elementos místicos y experimentales; hay componentes artísticos, casi diriamos estéticos a la vez que factores del más puro cientismo".

Muchas de sus lecciones, especialmente sobre medicina hipocrática y paracelsiana, se encuentran publicadas en la revista ya desaparecida "Medicina Moderna".

El doctor Marín Rojas nació en Talca en marzo de 1900 y después de efectuar sus estudios secundarios, inició los de Medicina en la Universidad de Chile, obteniendo el título de médico cirujano el 24 de octubre de 1921. Ingresó como ayudante a la Clínica Quirúrgica del profesor Sierra, al mismo tiempo que desempeñaba cargos de la especialidad y de venereólogo en los Dispensarios de la Junta de Beneficencia de Santiago. Al cabo de pocos años abandonó la capital para ingresar a la Armada Nacional,

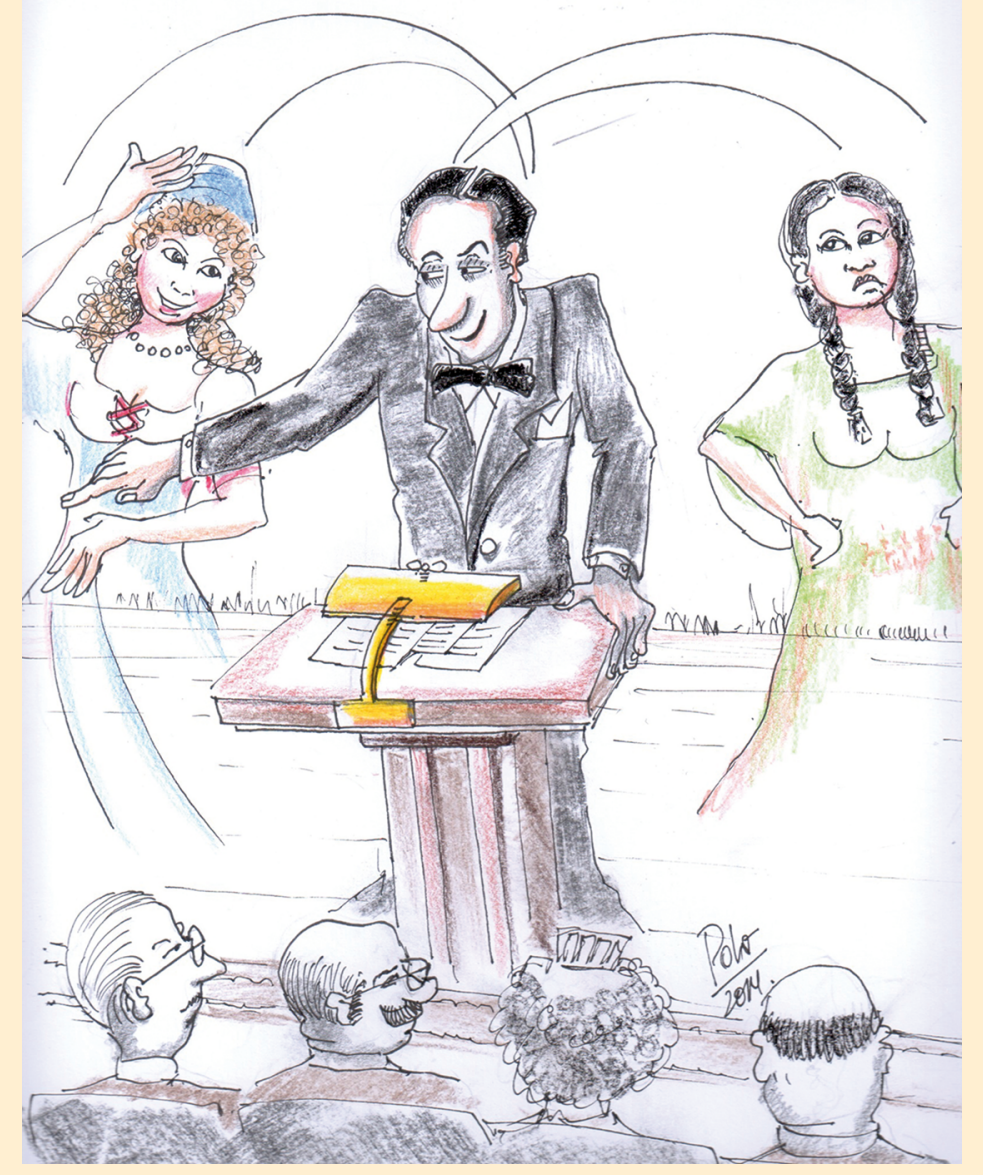




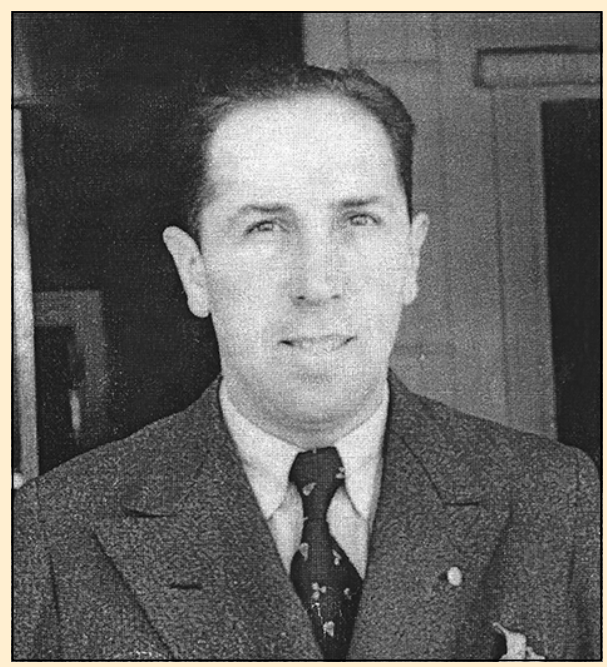

Doctor Juan Marín Rojas (1900-1963).

alcanzando el grado de cirujano capitán de corbeta. En 1929 publicó su libro de poesías "Looping".

Mientras permaneció en la Marina, sirvió como cirujano en los hospitales navales de Valparaíso y Punta Arenas, viajando en comisión de servicio por diversos países europeos. Fruto de este contacto, fue su magnífica obra "Clínica y Maestros en Inglaterra y Francia" (1931).

Retirado de la Armada, se entregó con fervor a tareas literarias y periodísticas. Sus escritos, preferentemente de crítica llenaron las páginas de la prensa chilena y de los demás países americanos. Nombraremos algunos: "Consideraciones acerca del secreto profesional y de la Medicina", "Margarita, el aviador y el médico", "Paralelo 53 Sur" (premio municipal de 1936), "El secreto del doctor Baloux" y varios más.

Atraído más tarde por la diplomacia, fue designado en junio de 1939, Encargado de Negocios y Cónsul de Chile en China. En 1944 sirvió el mismo cargo en El Salvador; luego en Egipto, Siria y Líbano, con sede en el Cairo. El año 1948, Encargado de Negocios en la India y funcionario de la Cancillería, Santiago, el año 1953.

Desligado de sus funciones diplomáticas, se reintegró a sus tareas literarias y periodísticas, éstas en "El Mercurio" de Santiago y en 1954, la Sociedad de Escritores de Chile lo nombró presidente de la institución.

La excepcional cultura, condiciones de sagacidad, capacidad organizadora, además de gran inquietud, lo llevaron en 1959 a desempeñar el cargo de Director del Departamento Cultural de la Organización de Estados Americanos (OEA).

El doctor Marín falleció el año 1963.

En las líneas que siguen transcribimos, casi en su totalidad, su "Ensayo sobre el origen de la sífilis", publicado en octubre de 1933 en "Medicina Moderna". Tema que aún concita gran interés en médicos e historiadores ${ }^{1-4}$.

\section{Introducción}

Es frecuente oír decir que la sífilis es tan vieja como la humanidad. Quienes así opinan se basan en algunas vagas nociones históricas y también en los hallazgos arqueológicos de cráneos fósiles, del período de la gran civilización egipcia y de la época de la cultura asiriobabilónica. Las perforaciones circulares encontradas en estos cráneos fueron interpretadas erróneamente por algunas escuelas medico-históricas como demostraciones visibles y evidentes de la existencia de lesiones destructivas (gomas) en los huesos de los antepasados primitivos.

La propia nariz de Sócrates ha sido reputada prueba fidedigna de que la sífilis existió por lo menos en la Grecia del Gran Siglo. Sin embargo, a ciencia cierta, se llegó a la conclusión que aquellas pérdidas de sustancia, regulares, redondeadas, fueron obra de los primitivos cirujanos que practicaban la trepanación de acuerdo al concepto demoníaco de la enfermedad, para expulsar del cuerpo enfermo los malos espíritus, conociéndose tanto los instrumentos utilizados con tal objeto, así como algunas formulas anestésicas hechas con yerbas como la mandrágora, el beleño, el hiosíamo, etc.

\section{La aparición de la sífilis en el siglo XV}

Ha dicho Voltaire, que "la sifilis es una enfermedad con genealogia". Juan Marín se pregunta cómo interpretar esta frase del "agudo satírico de las letras francesas": ¿quiso realmente decir que esta enfermedad ha adquirido sello de abolengo por su antigüedad? ¿O bien aludió cáusticamente al gran número de personajes encumbrados que desde la aparición de la sífilis en Europa fueron alcanzados por ella?

Es una verdad indudable desde la irrupción de la enfermedad en forma epidémica, en el panorama de la patología europea, que hace sus víctimas "en la choza del mendigo como en el palacio real". Al finalizar el siglo XV, enferma el gran Francisco I de Francia, el rey galante, el monarca guerrero, "que tendió la mano al pobre y envejecido Leonardo de Vinci", obsequiándole un castillo para que fuera allí a exhalar los últimos destellos de su genio. Se sabe que este rey fue tratado con ciertas píldoras famosas secretamente guardadas por el legendario pirata Barba Roja, en cuya composición existía el mercurio metálico crudo.

Enfermaron de sífilis Alonso y Juan de Borgia, el cardenal de Segovia y el más genial de los orfebres del 
Renacimiento, Benvenuto Cellini. Alberto Durero dejó un cuadro, en que se representa a si mismo desnudo y apuntando con el índice una sombra bajo su flanco izquierdo con la siguiente leyenda dirigida a su médico: "aparecen manchas en mi cuerpo y enflaquezco"... El célebre Ulrich Von Hutten, uno de los primeros en ocuparse de la sífilis, afirmaba que se trasmitía "por medio de un gusano alado" y enfermando de ella, recomendó el guayaco para su curación.

El origen del empleo de este vegetal en el tratamiento de la sífilis se encuentra en los indios americanos que lo tenían en gran estimación, usándolo en infusión para curarse los "males de bubas". Los españoles lo llamaron "palo santo" y lo adoptaron desde que tuvieron noticia de su uso. Cuando se supo esto en la Corte de España, se ordenó que todo barco que viniese del Nuevo Mundo, trajese una cantidad determinada de la milagrosa madera y no tardó en desarrollarse un gran comercio con el nuevo medicamento, pero después se comprobó que no poseía la menor acción sobre la enfermedad ${ }^{4}$.

\section{El momento epidemiológico y el medio histórico-social de la Europa mediterránea del Renacimiento}

Para representarse el fenómeno epidemiológico de la sífilis en la Europa mediterránea del Renacimiento, hay que remontar la perspectiva al medio histórico-social de la época, señalando el doctor Marín que "fue un período de grandes desplazamientos de masas humanas, de guerras y una edad en que el libertinaje y la corrupción de las costumbres alcanzó un nivel pocas veces igualado". Los ejércitos, en gran parte formados por mercenarios, iban acompañados por verdaderas muchedumbres de mujeres públicas. "Junto a los regimientos de la muerte caminaban los regimientos del amor".

Las grandes campañas de Francia contra el Reino de Nápoles, se caracterizaron por la vida licenciosa de las tropas. La prostitución alcanzó límites casi increíbles. En Venecia, ciudad que contaba con 300 mil habitantes, había 11.654 prostitutas. En Roma se contaban 6.800 y cuando el Papa Pío V, a petición de su médico Gaspar Torella quiso expulsarlas, la ciudad entera se levantó en son de protesta.

Todos los vicios tuvieron su florecimiento en este momento crítico en que se derrumbaba una cultura y nacía una nueva. Con razón, las grandes ciudades italianas del siglo XV han sido comparadas con las ciudades malditas de Sodoma y Gomorra.

Juan Marín afirma que "las grandes mutaciones espirituales parecen proyectarse en el campo físico $y$ material, alcanzando aun las misteriosas zonas de la patología”. Así con el Renacimiento, que significaba el retorno del espíritu crítico en el entendimiento humano por oposición al dogma medioeval y que en el orden político significaba el abatimiento de los gobiernos feudales ante las democracias de las nuevas ciudades italianas, también sufrieron violentos cambios los cuadros de la patología.

Sin que se sepa por qué, desaparecen del ambiente europeo, enfermedades que hasta ese momento habían sido su nota característica y fundamental. Se van de Europa la temida peste negra que abatía poblaciones enteras y la lepra. Pocos saben que esta última enfermedad, desconocida hoy en Europa, sentó allí sus reales durante varios siglos y bruscamente comenzó a decrecer hasta su total desaparición. Italia, España, Francia, estaban plagadas de leprosos: sólo en Francia había más de mil leproserías. Pero mientras estas enfermedades emprendían misteriosamente su viaje de partida, llegaban al continente anónimamente extrañas reemplazantes: la viruela, varicela y gripe; así, como pasa semejante a un huracán, el "sudor inglés" que, según cuenta Paracelso, mataba antes de veinticuatro horas.

La sífilis, enfermedad crónica que hoy conocemos, no es sino la sombra del terrible flagelo epidémico agudo, violento, destructor, que descendió sobre Europa. Se ha dicho que fue la prueba de fuego para la medicina del Renacimiento. Los grandes médicos de ese tiempo, los robustos iconoclastas que habían abatido la medicina galénica y aristotélica, la de los árabes y el bizantinismo, se encontraron frente a una enfermedad nueva. No podían ir a buscar en los libros antiguos su descripción y tratamiento, pues allí no figuraban. Con sus propios medios tuvieron que observarla, estudiarla y tratarla. Y los médicos del Renacimiento salieron airosos de la prueba: no en balde formaban en sus filas, Paracelso, Falopio, Berengario de Capri, que curó a Cellini; Botalio, Von Hutten; Massa que curó al cardenal de Segovia, Jacques de Bettancourt, etc.

Prosigue Marín Rojas: en el ambiente no médico, la aparición de esta enfermedad fue recibida con verdadero pánico; la iglesia la declaró un castigo de Dios por la corrupción de las costumbres y ordenó la más severa castidad, recomendando encomendarse a San Job para protegerse del mal. Los cabalistas, que eran legión (la magia tuvo un gran florecimiento durante los siglos XV y XVI) la atribuyeron a una conjunción de los planetas Marte y Saturno. En algunas ciudades se acuñaron medallas protectoras, entre ellas unas muy famosas que en su anverso representaban a Moisés con su vara de serpiente con la siguiente inscripción: "quien mire a la serpiente se librará del mal"; en el reverso aparecía Cristo crucificado y la inscripción que sigue: "quien confíe en mi encontrará salvación". El Concilio de Worms declaró la abstención de la blasfemia como medida profiláctica. 
Se ve, pues, que la desorientación reinaba en los espíritus. Había de venir un nuevo acontecimiento para producir una desorientación todavía mayor: el descubrimiento de América.

El descubrimiento de América. Leyenda del origen americano de la sífilis. Rodrigo Díaz de Isla. Figuras de la medicina partidarias y contrarias. Nombre de la enfermedad. Girolamo Fracastoro

El año 1492 un navegante descubría un nuevo mundo y regresaba al año siguiente a Europa. Nace entonces la leyenda del origen americano de la sífilis a la cual debían plegarse más tarde figuras ilustres de la medicina: Astruc, Van Sieten, Barduzzi, Virchov, Ivan Bloch. Entre los que se rebelaron contra este predicamento, están el gran historiador Karl Sudhoff (biógrafo de Paracelso) y un desconocido portugués, el doctor Antonio Núñez de Ribeiro Sánchez.

El punto de partida de la leyenda del origen americano de la sífilis fue la narración aparecida en 1504, del médico español Rodrigo Díaz de Isla, que acompañó en su primer viaje a Colón y que la describe entre los indígenas de la isla Española, contando cómo enfermaron algunos de los tripulantes, entre ellos Pinzón, piloto de la nave almirante. Varios años después, Gonzalo Oviedo, cronista de los viajes de Colón, afirma también el origen americano de las "bubas". Sin embargo, relata que la llegada de la sífilis a Europa se produjo durante el segundo viaje de Colón. Ruy Díaz y Fray Brentano de Monardes aseguran que fue en el primero.

De estas informaciones, según relata el doctor Marín Rojas, derivan todas las demás que dan por aprobado el origen americano de la sífilis.

El nombre de la enfermedad no nació de los tratados de medicina, sino de un libro de versos. Por aquellos años aparece en Verona, un hombrecito pequeño, rechoncho, hirsuto, cuyos ojos vivaces reflejaban su penetrante inteligencia. Se llamaba Girolamo Fracastoro y era músico, matemático, médico, lingüista, geólogo ilustre, poeta de amplio ritmo y depurado estilo. En 1539 escribe su "De sifilis si vemos bus gallicus", poema dedicado a su amigo el cardenal Bembo, en que narra las aventuras de un joven patricio llamado Sifilo que ultraja a Apolo, quien se venga enviándole una terrible enfermedad hasta entonces desconocida. Describe con maestría los detalles de le enfermedad, sus períodos, múltiples localizaciones y lesiones, terminando cuando Sifilo llega a un bosque bajo la sombra protectora de un "árbol sagrado", el guayabo, con el cual se cura.

La verdadera obra del genio de Fracastoro y que le da derecho a ocupar un sitio entre las grandes cumbres de la medicina, es su tratado "De contagione et contagiosis morbis", aparecido en 1546. Su teoría del contagio lo revela como el primer epidemiólogo y precursor directo de Pasteur en bacteriología. Establece tres formas de contagio: directo, indirecto por intermedio de ropas, objetos, etc. (llamados por él "fómites") y a distancia, por medio de unos pequeños corpúsculos que denominó "seminaria" o semillas. Anota Marín Rojas que "faltóle únicamente poner la palabra bacterio en lugar de seminaria, pues sus intuiciones son tan estupendas que, por ejemplo, al referirse a la "seminaria" de la tuberculosis dice "es tan resistente que hay que suponer, en determinadas circunstancias que adopta una forma como de enquistamiento. Le faltó aquí, poner la palabra espora para quedar de un salto maravilloso en pleno siglo $X I X^{\prime 4,5}$.

Vale la pena señalar la audacia de las concepciones de Fracastoro, que iban contra Galeno y por lo tanto resistidas. No hay que olvidar - dice Juan Marín- que muchos sostuvieron en aquel tiempo que la sífilis era producida por los "excesos venéreos" y no por contagio, concepto que sobrevivió durante muchos años ${ }^{4}$.

\section{Argumentos que prueban que la sífilis existió en Europa antes del primer viaje de Colon. Antonio Núñez de Ribeiro Sánchez}

Aquí el doctor Marín revela "que en gran parte dichos argumentos los ha tomado de una obra que el azar puso en sus manos, en una de sus excursiones bibliográficas a través de ese mundo miserable y admirable al mismo tiempo, de las librerías de viejo, a orillas del Sena, en París".

Allí por el año 1750 vivía, anónima y silenciosamente, un anciano médico portugués, Antonio Núñez de Ribeiro Sánchez, discípulo predilecto de Boerhave, con quien, después de haberse doctorado en Salamanca, estudió en Leyden. Un día Boerhave recibió desde Rusia el encargo para enviar tres discípulos suyos en calidad de médicos a la Corte Imperial. Núñez de Ribeiro fue uno de los elegidos. Su vida en la Corte de los Zares lo colocó en situaciones muy difíciles y pintorescas que vinieron a culminar cuando estalló la revolución que llevó al trono a Isabel Petrovna. Pero Núñez de Ribeiro no fue enviado a Siberia y gracias a servicios prestados a influyentes personajes, se le designó Consejero de Estado, cargo que declinó, solicitando que le dieran medios para regresar a su país. Sin embargo, se radicó en París y se consagró por entero a los estudios médicoshistóricos. En 1750 apareció la primera edición de su "Dissertation sur la maladie vénérienne dans laquelle on prouve qu'ellen'pointété apporté ed'Amerique (Disertación sobre la enfermedad venérea en la que 
se comprueba que no ha sido llevada desde América). Quince años después publicó su "Examen historique sur la maladie vénérienne en Europe" (Estudio histórico de la enfermedad venérea en Europa).

A continuación el doctor Juan Marín Rojas da a conocer los argumentos de Núñez de Ribeiro Sánchez sobre el no origen americano de la sífilis en Europa:

- Colón regresó de su primer viaje el 1 de marzo de 1493 a Lisboa y un mes después se encontraba en Barcelona. De los 90 hombres que llevó a América, dejó 38 en la isla Española, de modo que volvió con poco más de 40 a Europa. Habría que suponer que tan escaso contingente no sería capaz de contagiar a todo un continente.

- Ahora bien, en el año 1493, la sífilis hacia grandes estragos en Italia; ni España ni Portugal, donde desembarcaron los tripulantes, enfermaron con tal intensidad.

- Suponiendo que la sífilis fuera americana, habría que pensar que no era exclusiva de la isla de Santo Domingo, sino que existiría también en otras regiones del nuevo continente; sin embargo, Hernán Cortés, Vasco Núñez de Balboa, Francisco Pizarro, Diego de Almagro ni ninguno de sus numerosos cronistas la mencionaron.

- Fernando Colón, hijo del Almirante escribió la historia completa del viaje de su padre e ignoró en absoluto todo lo referente al mal venéreo entre los indígenas americanos.

Mucho caudal se ha hecho de lo relacionado con el sitio de Nápoles por Carlos VIII de Francia como elemento determinante del estallido de la epidemia. Según Núñez de Ribeiro Sánchez este es otro de los muchos mitos aceptados en esta leyenda. En 1495 no hubo propiamente sitio de Nápoles, pues el rey de Francia entró directamente al reino y se retiró libremente de la ciudad, derrotó a los aliados en campo raso y volvió a Francia, mientras Fernando II entraba a Nápoles protegido por las tropas de su aliado Gonzalo de Córdoba, el Gran Capitán.

- Un argumento definitivo, en contra de la tesis americana utilizó Núñez de Ribeiro Sánchez en sus escritos: se trata de una carta enviada por el profesor de griego Arias Barbosa, de Salamanca, a Pedro Martir, milanés, canónigo y lingüista, fechada en 1489, en que le contaba detalladamente haber sido atacado por la sífilis. Por lo tanto, existe la prueba evidente de que tres años antes del primer viaje de Colón, las "bubas" existían en España y seis años antes de la expedición de Carlos VIII y de Gonzalo de Córdoba sobre Nápoles.

Francisco de Villalobos, marqués de Astorga y médico, escribió un libro sobre sífilis y su tratamiento con mercurio y grasa, en el que establece que aquella apareció en España en 1489, coincidiendo con las cartas de Pedro Martir y Arias de Barbosa.

Bautista Fulgosi, cronista italiano dice que dos años antes que el rey Carlos VIII partiera para Italia, se descubrió una enfermedad, llamada en Francia "mal napolitano" y en Italia "mal francés". Esa fecha correspondería a 1492, cuando Colón recién salía a través del Atlántico.

Finalmente, el doctor Marín, estima sólo documentos de alto valor los obtenidos de los libros de Núñez de Ribeiro y las cartas de Arias Barbosa a Pedro Martir.

Concluyendo, Marín Rojas agrega: "mi intención al dar a conocer estos datos es mas bien establecer que debe primar al juzgar estos asuntos, un criterio ecléctico. De ninguna manera está probado que la sifilis haya sido llevada de América a Europa. Lo que está acreditado es que la sifilis existía en Europa Mediterránea, en el año 1492, antes de la partida de Colón, sin que sea posible determinar la fecha exacta de su irrupción en la patología. Frente a la afirmación del origen americano de la sifilis, Marín Rojas aspira "a dejar una duda, ya que no una convicción contraria"3-6.

\section{Resumen}

El doctor Juan Marín Rojas, primer profesor de Historia de la Medicina de la Universidad de Chile, médico naval, diplomático, escritor y crítico literario. Miembro de la Sociedad Internacional de Historia de la Medicina; Miembro Correspondiente para Chile del "Office de Documentation de Médecine et Pharmacie Militaire”, Lieja, Bélgica, del que se transcribe su "Ensayo sobre el origen de la sífilis", con antecedentes históricos interesantes y argumentos poco conocidos que afirman el no origen americano de la sífilis, si bien "aspira a dejar una duda, ya que no una convicción contraria".

\section{Referencias bibliográficas}

1.- Laval M E. El doctor Juan Marín Rojas, primer profesor de Historia de la Medicina de la Facultad de Medicina, Universidad de Chile. An Chil Hist Med 1959; 1: 355-7.

2.- Zúñiga R S. Algunos antecedentes sobre los comienzos de la enseñanza de la historia de la medicina en Chile: el Dr. Juan Marín Rojas. An Chil Hist Med 2007; 17: 197-202.

3.- Marín R J. Introducción al estudio de la Historia de la Medicina. Lección inaugural en la Universidad de Chile. An Chil Hist Med 1960; 2: 199-220.

4.- Marín R J. Ensayo sobre el origen de la sífilis. Med Moder 1933; 7: 1-8.

5.- Hudson E H. Examen histórico de la terminología de la sífilis. An Chil Hist Med 1962; 4: 69-95.

6.- Chateau A G. Leyendo a Juan Marín Rojas. An Chil Hist Med 1971; 13: 141-58. 